\title{
Probing Isomeric Differences of Phosphorylated Carbohydrates Through the Use of Ion/Molecule Reactions and FT-ICR MS
}

\author{
M. D. Leavell and Julie A. Leary \\ Department of Chemistry, University of California at Berkeley, Berkeley, California, USA
}

\begin{abstract}
Through the use of ion/molecule reactions and tandem mass spectrometry, phosphate position is assigned in both phosphorylated monosaccharides and oligosaccharides. In previous work [1,2] phosphate moieties of monosaccharides were stabilized under collisional activation, by first derivatizing the deprotonated monosaccharide with trimethyl borate through an ion/molecule reaction, and the phosphate position determined through marker ions generated in tandem mass spectra. In this work, the methodology is extended to larger phosphorylated oligomers employing chlorotrimethylsilane (TMSCl) as the ion/molecule reagent. Phosphorylated monosaccharides were first investigated to determine diagnostic ions for phosphate linkage in monomeric standards. It was observed that the diagnostic ions showed both linkage and some monosaccharide stereochemical information. Furthermore, it was observed that TMS addition stabilized the phosphate moiety under collisionally activated conditions. Upon identification of the diagnostic ions, the methodology was applied to lactose-1-phosphate. It was found that $\mathrm{TMSCl}$, stabilized the phosphate moiety upon collisional activation, and furthermore, the phosphate linkage could be determined through tandem mass spectrometric analysis. As a further extrapolation to biologically relevant problems, the methodology was applied to a lipophosphoglycan analog from the protozoan parasite Leishmania. This sample contains bridging phosphates which were converted to terminal phosphates through collision induced dissociation. The sample was then analyzed in the same manner as lactose-1-phosphate, yielding phosphate linkage information and stereochemical information. This study showed that, using the developed methodology, phosphate linkage can be determined from both monosaccharides and larger oligosaccharides; furthermore it is applicable to samples in which the phosphates are either terminating or bridging. (J Am Soc Mass Spectrom 2003, 14, 323-331) @ 2003 American Society for Mass Spectrometry
\end{abstract}

$\mathrm{P}$ hosphorylated carbohydrates are intimately involved in several biological processes such as glycolysis [3], as glycosyl donors in the biosynthesis of oligosaccharides [4], and as molecular recognition markers for the trafficking of lysosomal enzymes to the lysosome [5]. Phosphorylated lipooligosaccharides (LOS) are major components of bacterial cell walls, where it is postulated that the pathogen may use these structures to evade the host's defense mechanisms and contribute to virulence [6-8]. In addition, phosphate modification is believed to stabilize the bacterial cell wall adding to membrane coherence [8], or even to aid in the adherence of the bacteria to host cells [6]. Other phosphorylated glycolipids, termed lipophos-

Published online March 10, 2003

Address reprint requests to Dr. J. A. Leary, Department of Chemistry, University of California at Berkeley, Berkeley, CA 94720, USA. E-mail: leary@socrates.berkeley.edu phoglycans (LPG), have been implicated in the virulence of the parasite Leishmania [9-11].

The infectious cycle of Leishmania, a protozoan parasite and the causative agent of the disease leishmaniasis, is dependant on the LPGs found on the organism's cell surface. The parasite exhibits a two-phase life cycle, where it alternates between the bloodfeeding sandfly vector and a mammalian host [9-11]. In these organisms, the parasite resides in exceptionally harsh environments. For example, it lives in the gut of the sandfly, where it must resist digestive enzymes and expulsion during the bloodmeal. Similarly, in the mammalian host the parasite thrives in the phagolysosome, where it must resist hydrolytic enzymes and microbiocidal oxidative burst $[9,10]$. LPG is a major component of the parasite's cell membrane, and has been implicated in the survival and overall persistence of the organism. For example, it has been shown that the binding/ release of the parasite to/from the gut of the sandfly is 
governed by modifying the length of the phosphodisaccharide domain within the LPG. In the mammalian host, LPG has been shown to mediate the attachment of Leishmania to macrophages; furthermore, it is postulated that the anionic nature of the LPG affords the parasite protection from hydrolytic enzymes and oxidative attack $[9,10]$.

In order to investigate the structure/function relationship of phosphates in the aforementioned and other undiscovered examples, the location of phosphate attachment and the overall structure of phosphorylated glycoconjugates must be determined. Analysis of phosphate position within glycoconjugates is a challenging task, and oftentimes a direct structural connection between phosphate position and biological function cannot be elucidated. This limitation is often due to the lack of analytical methods to analyze phosphate position. Mass spectrometry is well suited for such an analysis, given that it is often the technique of choice for structural elucidation of carbohydrates, proteins, and lipids, as is evidenced by a book devoted to this subject [12]. However, analysis of phosphate positioning within oligosaccharides to date has been relatively unsuccessful by mass spectrometric methods. This is due to the facile loss of phosphate-containing moieties during tandem mass spectrometry, thus obviating determination of phosphate position [1, 2]. For example, in tandem mass spectrometric analysis of underivatized phosphate-containing oligosaccharides (or peptides/proteins), phosphate cleavage results in such species as $\mathrm{PO}_{3}^{-}, \mathrm{H}_{2} \mathrm{PO}_{4}^{-}, \mathrm{HPO}_{3}$, or $\mathrm{H}_{3} \mathrm{PO}_{4}[1,2,13]$. Thus, either the charge is lost from the carbohydrate (and the neutral saccharide can no longer be analyzed), or the phosphate moiety is lost from the sugar, and an alkoxide results at its former position. While diagnostic ions may often be utilized for the determination of phosphate attachment in underivatized peptides, such ions are either not observed or of low abundance in tandem mass spectrometric studies of carbohydrates. Thus, cleavage of phosphate-containing groups makes the phosphate position indeterminate. This problem is particularly problematic in the analysis of larger phosphorylated oligomers where several stages of tandem mass spectrometry must be utilized for full structural characterization, and thus phosphate cleavage is even more prevalent. Previous methods of characterizing sugar phosphate monosaccharides have utilized trimethylsilyl derivatization coupled to GC/MS [14, 15], HPLC/MS/MS [16], and tandem mass spectrometry [17]. However, until recently a purely mass spectrometric method for the characterization of phosphate positioning within monosaccharides and phosphorylated oligomers had not been developed.

Recently, research in this laboratory explored the combination of ion/molecule reactions and tandem mass spectrometry for the rapid determination of phosphate position within phosphorylated monosaccharides $[1,2]$. The ion/molecule reactions stabilized the phosphate moiety under collisionally activated conditions, allowing structurally significant product ions to be generated and the phosphate position to be determined. The analytical application of ion/molecule reactions has long been realized and is currently of much interest as is evidenced by two recent reviews $[18,19]$. Other recent examples include those by Kenttämaa and coworkers who utilized ion/molecule reactions to differentiate isomeric species such as diols $[20,21]$ and steroids [22]. In other studies, ion/molecule reactions have been utilized to develop a potential gas phase sequencing method for peptides [23], to determine enantiomeric excess [24-26], and to explore non-covalent interactions [27]. In addition, McLuckey and coworkers have employed ion/ion proton transfer reactions to enrich specific charge states of protein ions as part of their "ion parking" methodology [28].

In previous studies, trimethyl borate was the ion/ molecule reagent employed to determine phosphate position in phosphorylated monosaccharides [1, 2]. In order to extend upon the current method, several new ion/molecule reagents were investigated. These included several boron-containing reagents, however these suffered from the prevalent neutral losses of the boron-attached groups. The most promising reagent was found to be chlorotrimethylsilane (TMSCl). Previously, McLuckey and $\mathrm{O}^{\prime}$ Hair studied the reaction between TMSCl and nucleic acid anions [29]. They found that the modification of the phosphate ester with TMS allowed sequence information to be gained since the dissociation of the modified and unmodified species was drastically changed. In this study, the application of TMSCl to phosphorylated mono- and oligosaccharide isomers is investigated. In particular, this methodology has been improved since non-specific losses are no longer observed, as they were previously with trimethylborate $[1,2]$. Furthermore, this methodology is now extended from monosaccharides to larger oligomers such as lactose-1-phosphate and a synthetic LPS analog [30]. This study illustrates the flexibility of the method for characterizing isomers and larger oligomers.

\section{Experimental}

\section{Instrumentation}

All experiments were performed on a Bruker-Daltonics (Billerica, MA) Apex II FT-ICR mass spectrometer equipped with a 7.0 tesla actively shielded superconducting magnet. Ions were generated using electrospray ionization in the negative ion mode (Analytica, Branford, CT). All monosaccharides were sprayed at a concentration of $30 \mu \mathrm{M}$ in $1: 1 \mathrm{MeOH}: \mathrm{H}_{2} \mathrm{O}$ with no added acid or base. Ions were accumulated external to the FT-ICR MS trapping cell [31] in a hexapole ion guide for 0.5-2.0 s. After accumulation the ions were transferred to the FT-ICR MS cell, where they were trapped and analyzed as explained below.

Tandem mass spectrometry $\left(\mathrm{MS}^{\mathrm{n}}\right)$ experiments were 


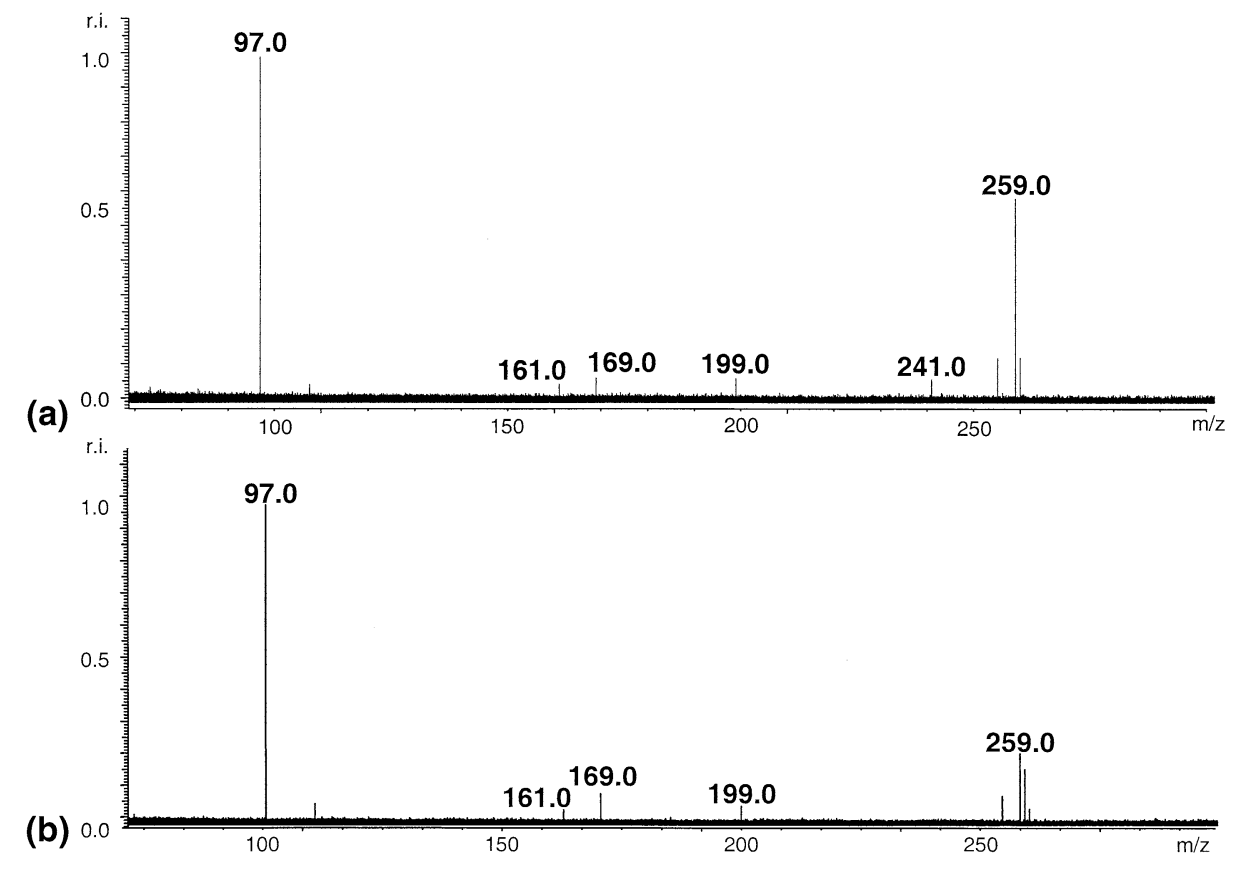

Figure 1. Product ion spectrum from the dissociation of (a) [glucose-1-phosphate-H] ${ }^{-}(\mathrm{Glc} 1 \mathrm{P})$ and (b) [glucose-6-phosphate-H] ${ }^{-}$(Glc6P).

performed by first isolating the precursor ion by a CHEF [32] isolation sweep, followed by "cleanup" shots if necessary. SORI-CID [33] was accomplished by lowering the cell pressure to $\sim 1 \times 10^{-6}$ mbar range, while exciting the ion off resonance for $250 \mathrm{~ms}$. The offresonance amplitude was adjusted to give nearly complete attenuation of the precursor ion signal. Following excitation, a pumpdown time of $3 \mathrm{~s}$ allowed the product ions to be detected under high-resolution conditions.

For ion/molecule reactions chlorotrimethylsilane (TMSCl) was pulsed into the FT-ICR MS cell after the ion-trapping event for $100 \mathrm{~ms}-5 \mathrm{~s}$. The ion/molecule reagent was degassed by cycling through several freeze-pump-thaw cycles.

\section{Chemicals and Materials}

All phosphorylated monosaccharides and disaccharides were purchased from Sigma Chemical Company (St. Louis, MO). Chlorotrimethylsilane was purchased from
Aldrich Chemical Company (Milwaukee, WI). The lipophosphoglycan was kindly provided by Professor Michael A. J. Ferguson and Dr. Andrei Nikolaev (University of Dundee, Scotland, UK) [30]. All solvents were purchased from Fisher (Fairborn, NJ) and the solvents were of HPLC grade.

\section{Results and Discussion}

\section{Stabilization of Phosphates and Determination of Phosphate Position}

Analysis of phosphate position using mass spectrometry is often problematic as is depicted in Figure 1. When either glucose-1-phosphate (Glc1P) or glucose-6phosphate (Glc6P) is ionized, isolated and subjected to collisionally activated conditions, information as to the phosphate position is lost. For example $\mathrm{m} / \mathrm{z} 199.0$ and 169.0 result from cross ring cleavages of the monosaccharide ring and observed as loss of $\mathrm{C}_{2} \mathrm{H}_{4} \mathrm{O}_{2}$ and

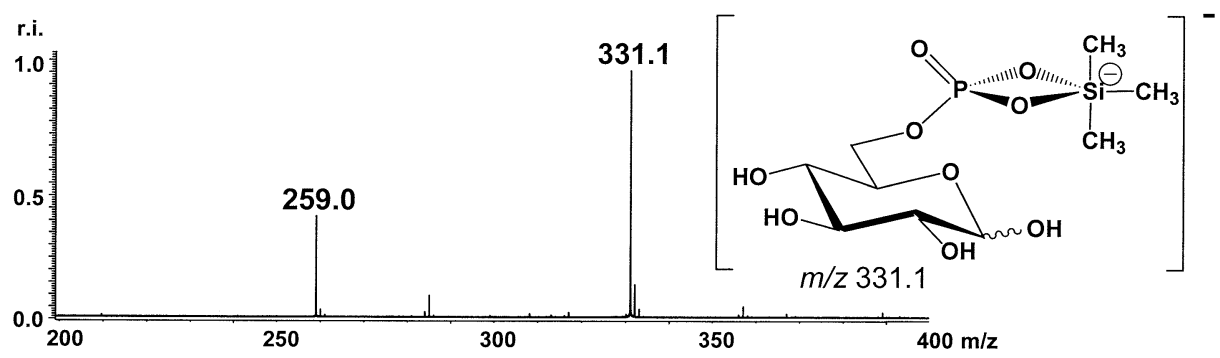

Figure 2. The ion/molecule reaction of glucose-6-phosphate $(\mathrm{m} / \mathrm{z} 259.0)$ with chlorotrimethylsilane (TMSCl). The reaction product ([Glc6P/TMSCl-HCl] $]^{-} ; \mathrm{m} / z$ 331.1) results from addition of TMSCl to the $\mathrm{Gl}_{6} \mathrm{P}^{-}$followed by elimination of $\mathrm{HCl}$. 

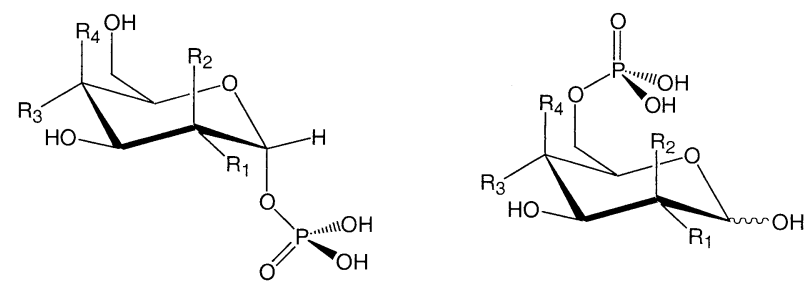

Hexose- $\alpha$-1-Phosphate (Hex 1P)

Hexose-6-Phosphate (Hex6P)

\begin{tabular}{lllll}
\hline & $\mathrm{R}_{1}$ & $\mathrm{R}_{2}$ & $\mathrm{R}_{3}$ & $\mathrm{R}_{4}$ \\
\hline Glucose & $-\mathrm{OH}$ & $-\mathrm{H}$ & $-\mathrm{OH}$ & $-\mathrm{H}$ \\
Galactose & $-\mathrm{OH}$ & $-\mathrm{H}$ & $-\mathrm{H}$ & $-\mathrm{OH}$ \\
Mannose & $-\mathrm{H}$ & $-\mathrm{OH}$ & $-\mathrm{OH}$ & $-\mathrm{H}$ \\
\hline
\end{tabular}

Figure 3. Structure of the monosaccharide phosphates investigated in this study.

$\mathrm{C}_{3} \mathrm{H}_{6} \mathrm{O}_{3}$, respectively. Neutral loss of phosphoric acid is also observed at $\mathrm{m} / \mathrm{z}$ 161.0, however, the predominant product ion observed in this spectrum is at $\mathrm{m} / \mathrm{z} 97.0$ and corresponds to the dihydrogen phosphate anion. These data illustrate the difficulty in analyzing phosphorylated carbohydrates (or peptides), in which the phosphate group is lost upon CID. Furthermore, the low abundance of the other product ions containing phosphate in the spectrum does not allow further analysis by subsequent stages of mass spectrometry.

Figure 2 shows the ion/molecule reaction between
Glc6P and TMSCl. Glc6P is observed at $m / z$ 259.0, which corresponds to a singly-deprotonated hexose phosphate. Upon pulsing TMSCl into the ICR cell for $3 \mathrm{~s}$, a single reaction product is observed at $\mathrm{m} / \mathrm{z} 331.1$. This ion is formed through addition of TMSCl and elimination of $\mathrm{HCl}$. The reaction was carried out for all six phosphorylated monosaccharide isomers shown in Figure 3. In all cases, this reaction yielded a single reaction product at $m / z 331.1$ ([HexP/TMSCl- $\mathrm{HCl}]^{-}$, where HexP $=$ hexose-phosphate).

Upon reacting deprotonated Glc1P and Glc6P with TMSCl and subjecting these reaction products to collisionally activated conditions, several product ions result (Figures 4a and b). For example, $\mathrm{m} / \mathrm{z} 169.0$ and 241.0 correspond to loss of the hexose moiety $\left(-\mathrm{C}_{6} \mathrm{H}_{10} \mathrm{O}_{5}\right)$ and a cross ring cleavage $\left(-\mathrm{C}_{3} \mathrm{H}_{6} \mathrm{O}_{3}\right)$, respectively. Also, generation of the metaphosphate anion $(\mathrm{m} / \mathrm{z} 79.0$, $\left.\mathrm{PO}_{3}^{-}\right)$is observed. More importantly, there are two differences observed between the Glc1P and Glc6P spectra. These are a loss of $\mathrm{H}_{2} \mathrm{O}(\mathrm{m} / \mathrm{z}$ 313.1) for the 1-linked isomer and a loss of $\mathrm{C}_{2} \mathrm{H}_{4} \mathrm{O}_{2}(\mathrm{~m} / z$ 271.0) for the 6-linked isomer. These ions are consistently observed for these isomers and are therefore classified as diagnostic ions (Table 1). Similar differences are observed for the galactose and mannose isomers as well (Table 1). For example, loss of $\mathrm{H}_{2} \mathrm{O}(\mathrm{m} / \mathrm{z} 313.1)$ is observed for galactose-1-phosphate (Gal1P) and absent for galactose6-phosphate (Gal6P), while loss of $\mathrm{C}_{2} \mathrm{H}_{4} \mathrm{O}_{2}(\mathrm{~m} / \mathrm{z}$ 271.0) and $\mathrm{C}_{3} \mathrm{H}_{6} \mathrm{O}_{3}(\mathrm{~m} / \mathrm{z} 241.0)$ is observed for mannose-6phosphate (Man6P), but absent for mannose-1-phosphate (Man1P). Thus, by comparing the diagnostic ions

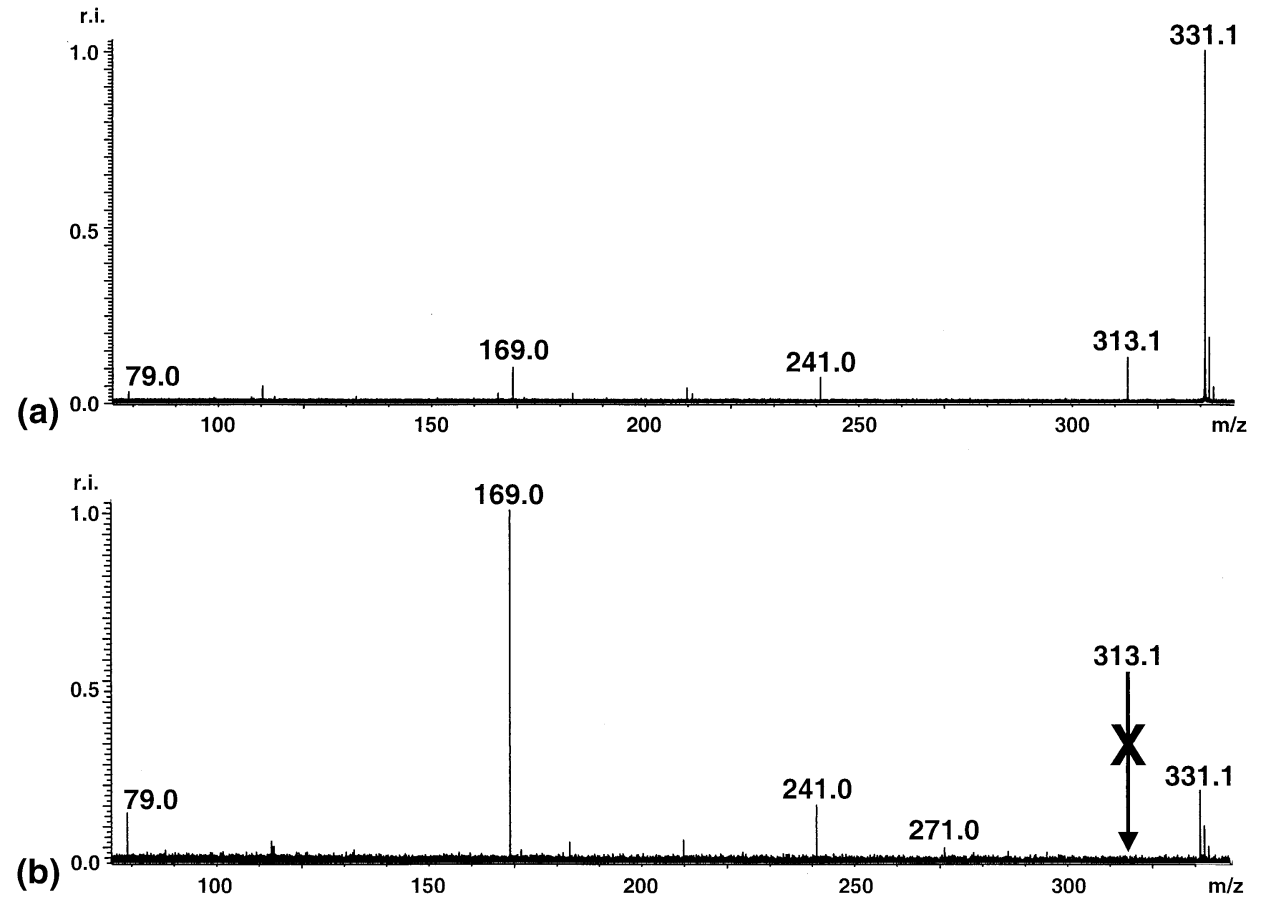

Figure 4. Product ion spectrum of (a) $[\mathrm{Glc} 1 \mathrm{P} / \mathrm{TMSCl}-\mathrm{HCl}]^{-}$and (b) [Glc6P/TMSCl-HCl ${ }^{-}$, illustrating the diagnostic ions for the glucose-phosphate isomers. 
Table 1. Product ions observed when the various $[\mathrm{HexP} / \mathrm{TMSC} 1-\mathrm{HCl}]^{-}$precursors are subjected to collisionally activated conditions

\begin{tabular}{lccccc}
\hline & $\mathrm{m} / \mathrm{z} 313.1\left(-\mathrm{H}_{2} \mathrm{O}\right)$ & $\mathrm{m} / \mathrm{z} 271.0\left(-\mathrm{C}_{2} \mathrm{H}_{4} \mathrm{O}_{2}\right)$ & $\mathrm{m} / \mathrm{z} 241.0\left(-\mathrm{C}_{3} \mathrm{H}_{6} \mathrm{O}_{3}\right)$ & $\mathrm{m} / \mathrm{z} 169.0\left(-\mathrm{C}_{6} \mathrm{H}_{10} \mathrm{O}_{5}\right)$ & $\mathrm{m} / \mathrm{z} 79.0\left(\mathrm{PO}_{3}{ }^{-}\right)$ \\
\hline \hline Glc1P & $\mathrm{X}$ & & $\mathrm{X}$ & $\mathrm{X}$ & $\mathrm{X}$ \\
Gal1P & $\mathrm{X}$ & & $\mathrm{X}$ & $\mathrm{X}$ & $\mathrm{X}$ \\
Man1P & & $\mathrm{X}$ & $\mathrm{X}$ & $\mathrm{X}$ & $\mathrm{X}$ \\
$\mathrm{Glc6P}$ & & $\mathrm{X}$ & $\mathrm{X}$ & $\mathrm{X}$ & $\mathrm{X}$ \\
Gal6P & & $\mathrm{X}$ & $\mathrm{X}$ & $\mathrm{X}$ & $\mathrm{X}$ \\
Man6P & & & & $\mathrm{X}$ \\
\hline
\end{tabular}

generated from these samples, the phosphate position may be determined.

It is equally important to note that not only can the linkage of the phosphate be determined, but in select cases, the stereochemistry of the monosaccharide can be probed. For example, when the phosphate moiety is in the 1-position, loss of $\mathrm{H}_{2} \mathrm{O}(\mathrm{m} / \mathrm{z} 313.1)$ and $\mathrm{C}_{3} \mathrm{H}_{6} \mathrm{O}_{3}(\mathrm{~m} / \mathrm{z}$ 241.0) are observed for the Glc1P and Glc6P isomers; however, these product ions are not observed for the Man1P isomer. This is likely due to the fact that the phosphate and the $\mathrm{C}(2)-\mathrm{OH}$ are anti in the Man1P isomer and syn in the Glc1P and Gal1P isomers. Similar axial and equitoral positioning of hydroxyl groups have been found to be important in determining the stereochemistry of hexose isomers upon CID in the analysis of transition metal-ligand derivatized monosaccharides [34-37] and in the stereochemical analysis of cyclic diols [20, 21, 38]. Thus, it appears that the stereochemistry of the hydroxyl group adjacent to the phosphate plays a role in the product ions observed upon subject- ing the $[\mathrm{HexP} / \mathrm{TMSCl}-\mathrm{HCl}]^{-}$complexes to collisionally activated conditions.

\section{Lactose-1-Phosphate}

With the successful application of $\mathrm{TMSCl}$ to deprotonated phosphorylated monosaccharides, focus turned to the investigation of larger phosphorylated oligomers. In particular, lactose-1-phosphate was investigated to determine the applicability of this methodology to phosphorylated disaccharides. Reaction of lactose-1phosphate (Lac1P) with TMSCl yielded a reaction product at $m / z$ 493.1, which is analogous to the addition/ elimination reaction product observed for the phosphorylated monosaccharides (i.e., [Lac1P/TMSCl$\mathrm{HCl}]^{-}$). Upon collisional activation of the ion/molecule reaction product, several product ions are observed (Figure 5a). For example, several neutral losses such as $\mathrm{H}_{2} \mathrm{O}\left(m / z\right.$ 475.1) $\mathrm{C}_{2} \mathrm{H}_{4} \mathrm{O}_{2} / \mathrm{H}_{2} \mathrm{O}\left(m / z\right.$ 415.1) and $\mathrm{C}_{3} \mathrm{H}_{6} \mathrm{O}_{3}$ $(\mathrm{m} / \mathrm{z}$ 403.1) are present in the spectrum as well as

(a)

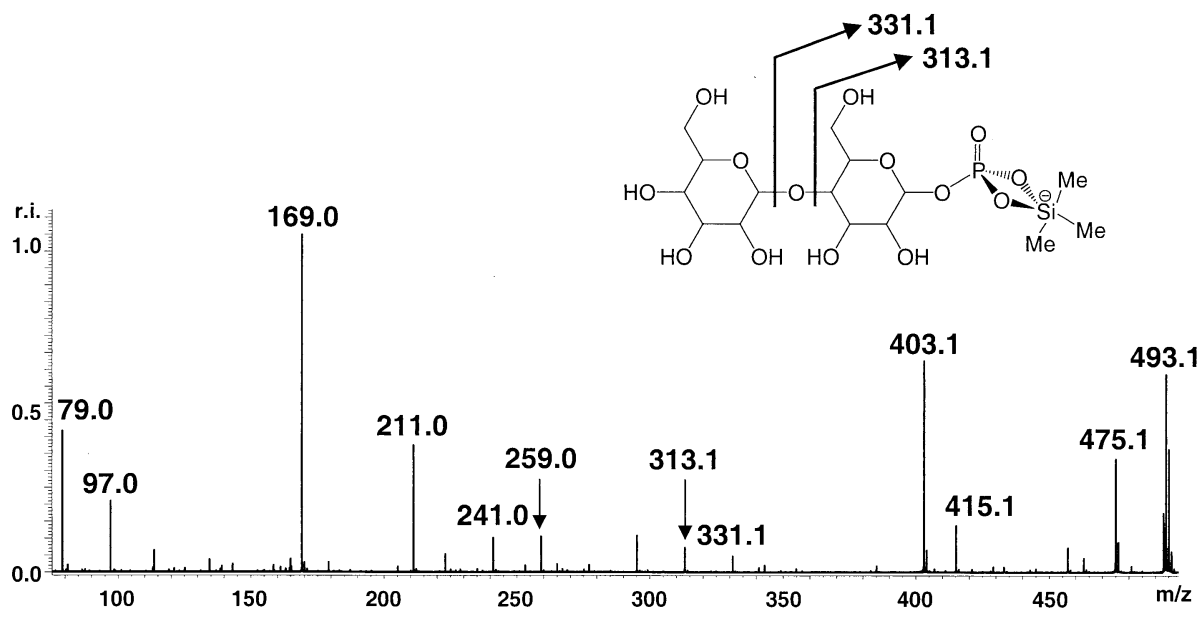

(b)

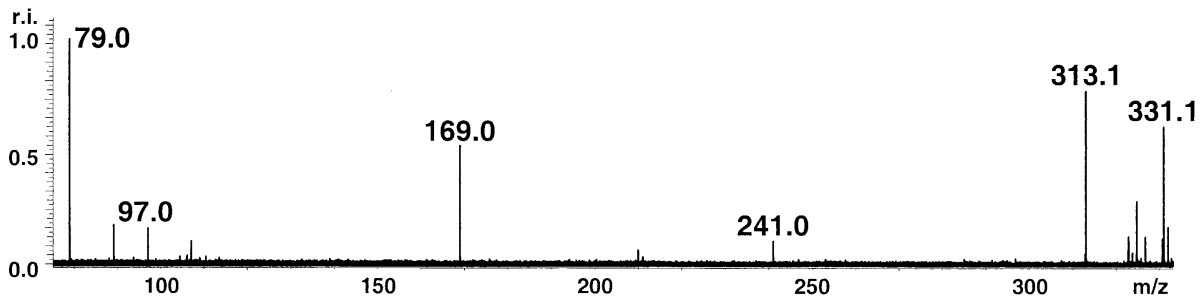

Figure 5. MS/MS of ion molecule reaction product (a) $[\mathrm{Lac1P} / \mathrm{TMSCl}-\mathrm{HCl}]^{-} \mathrm{m} / z$ 493.1, and (b) $\mathrm{MS}^{3}$ of $m / z$ 331.1, generated from glycosidic cleavage of the original lactose species ([Lac1P/TMSCl-anhex$\mathrm{HCl}]^{-}$. 
glycosidic cleavage ions at $\mathrm{m} / \mathrm{z} 259.0$ and 331.1 generating a free phosphorylated monosaccharide and one derivatized with TMS, respectively. Interestingly, the base peak in the spectrum, $\mathrm{m} / \mathrm{z} 169.0$, is generated from the cleavage of the phosphate moiety derivatized with TMS [i.e., $\left.\mathrm{HO}_{3} \mathrm{P}-\mathrm{O}-\mathrm{Si}(\mathrm{Me})_{3}\right]^{-}$. This ion was also observed from collisional activation of the TMS derivatized monosaccharide phosphates (Figure 4, Table 1). It is important to note that the normal pathways of phosphate loss yielding the metaphosphate anion $\left(\mathrm{PO}_{3}^{-}\right.$ $\mathrm{m} / \mathrm{z}$ 79.0) and the dihydrogen phosphate anions $\left(\mathrm{H}_{2} \mathrm{PO}_{4}^{-} ; m / z\right.$ 97.0) are minimized upon collisional activation of the TMS derivatized disaccharide. Thus, addition of the TMS reagent allows for stabilization of the phosphate moiety even when applied to larger oligomers. Further isolation and collisional activation of $\mathrm{m} / \mathrm{z} 331.1$ yields the spectra depicted in Figure 5b. Upon comparison of the $\mathrm{MS}^{3}$ data of the Lac1P sample (Figure $5 b$ ) with the MS ${ }^{2}$ spectra of the Glc1P and Glc6P (Figure 4a and b, Table 1) standards, it is clear that the phosphorylated hexose monomer in Lac1P is phosphorylated in the 1-position and not in the 6-position. This is evidenced through the abundant loss of water present in the Glc1P and Lac1P standards, which are not present in Glc6P. Furthermore, the loss of $\mathrm{H}_{2} \mathrm{O}$ suggests that the hydroxyl group adjacent to the phosphate is cis rather than trans. These results are consistent with a phosphate linked to the 1-position in either glucose or galactose.

\section{Application to a Lipophosphoglycan from Leishmania}

Encouraged by the results from Lac1P, a chemically synthesized lipophosphoglycan (LPG) analog [30] from the Leishmania parasite was investigated (Figure 6a). LPG is made up of repeating disaccharide units, which are elongated on a lipid core. Previous studies by Ferguson and coworkers showed that lipophosphoglycans can be analyzed using ESI-MS/MS product ion scanning mode [39]. While their method allows for the determination of the repeating moieties in a LPG sample, it does not provide phosphate linkage information. Therefore, the ion/molecule methodology was applied to ascertain its effectiveness in determining phosphate linkage in a larger oligomer. Furthermore, it allows the investigation of a molecule in which the phosphate is internal rather than terminal. Ionization of this LPG yielded a doubly charged ion, which is observed at $\mathrm{m} / \mathrm{z}$ 643.7 (Figure 6a). Since all previous applications of the methodology employed a singly-charged precursor ion, CID was undertaken on the intact molecular species to see if a singly-charged ion would result. Upon collisional activation several ions are formed, all of which result from the cleavage of the LPG backbone around the bridging phosphate moieties. This type of behavior has been observed before by Ferguson et al., where cleavage of the LPG backbone around the phosphate moieties is in preference to other types of cleavages (i.e., cross ring cleavages) [39]. Two of these ions, $\mathrm{m} / \mathrm{z} 481.1$ and 559.2, result in terminating phosphate residues. Since $m / z 481.1$ is the base peak in the spectrum, it was chosen for further analysis.

Reaction of $m / z 481.1$ with TMSCl yielded a singlycharged species (through elimination of the chloride anion) at $m / z$ 1035.3. Previous studies by McLuckey and coworkers have shown that TMSCl undergoes charge elimination when reacting with multiply-charged oligonucleotides, while for singly charged oligonucleotides, the addition/elimination pathway is favored [29]. Collisional activation of $\mathrm{m} / \mathrm{z} 1035.3$ (Figure 6c) resulted in several product ions, all of which are glycosidic cleavage products. It is important to note that addition of the TMSCl can occur at either phosphate moiety. Therefore, pairs of peaks are observed in the product ion spectrum from those ions with and without addition of the trimethyl silyl group. For example, $m / z 403.1$ and 475.1 result from cleavage of the disaccharide portion on the non-reducing end. However, $\mathrm{m} / \mathrm{z} 403.1$ does not contain the TMS group in the terminating phosphate moiety, while $\mathrm{m} / \mathrm{z} 475.1$ does show TMS derivatization at the same location (Figure 6c). Another pair of ions is observed at $\mathrm{m} / \mathrm{z} 259.0$ and 331.1. These ions result from cleavage of the glycosidic bond between the terminating and the penultimate monosaccharide and correspond to the $[\mathrm{HexP}-\mathrm{H}]^{-}$anion and the $[\mathrm{HexP} / \mathrm{TMSCl}-$ $\mathrm{HCl}^{-}$complex respectively. Thus, a hexose-phosphate monosaccharide with and without TMS addition has been generated.

Isolation of $\mathrm{m} / \mathrm{z} 259.0$ and 331.1 and reaction with TMSCl results in full conversion of $\mathrm{m} / \mathrm{z} 259.0$ to 331.1. Collisional activation of $\mathrm{m} / \mathrm{z} 331.1$ (Figure 6d) yielded product ions that agree with a Gal6P standard run under identical conditions (Figure 6f). In particular, water loss is not observed in this product ion spectrum, which is known to be diagnostic for Gal1P (Figure 6e). Thus, the ion/molecule methodology can be applied not only to terminal phosphates, but also to phosphorylated oligosaccharides in which the phosphates are bridging. This analysis is accomplished by generating the terminal phosphate from collisional activation, followed by the ion/molecule reaction to stabilize the phosphate moiety. Once reacted, the newly generated phosphate is stabilized, allowing further analysis by tandem mass spectrometry.

\section{Conclusions}

Low energy loss of phosphate from carbohydrates often occurs under collisionally activated conditions, which obviates determination of the phosphate linkage position by tandem mass spectrometric methods. In previous work [1,2], phosphate linkage position was accomplished through reaction of the phosphate moiety with trimethyl borate (TMB), which stabilized the phosphate moiety under collisional activation. Upon reaction with $\mathrm{TMB}$, phosphate linkage position and unambiguous 


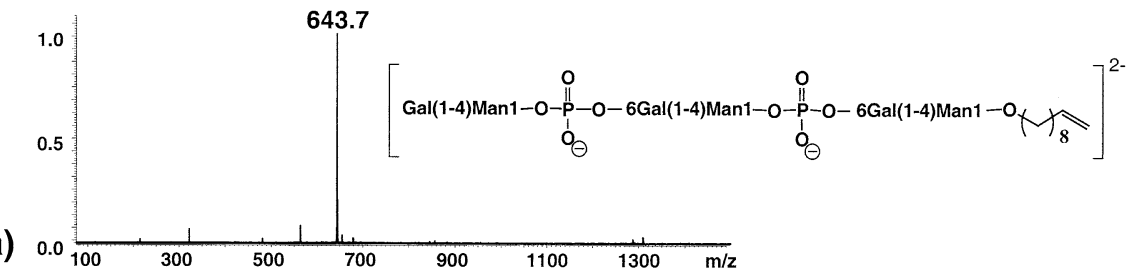

(b)

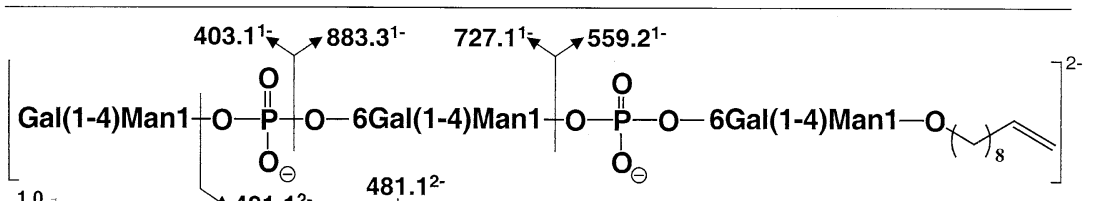

\section{(c)}
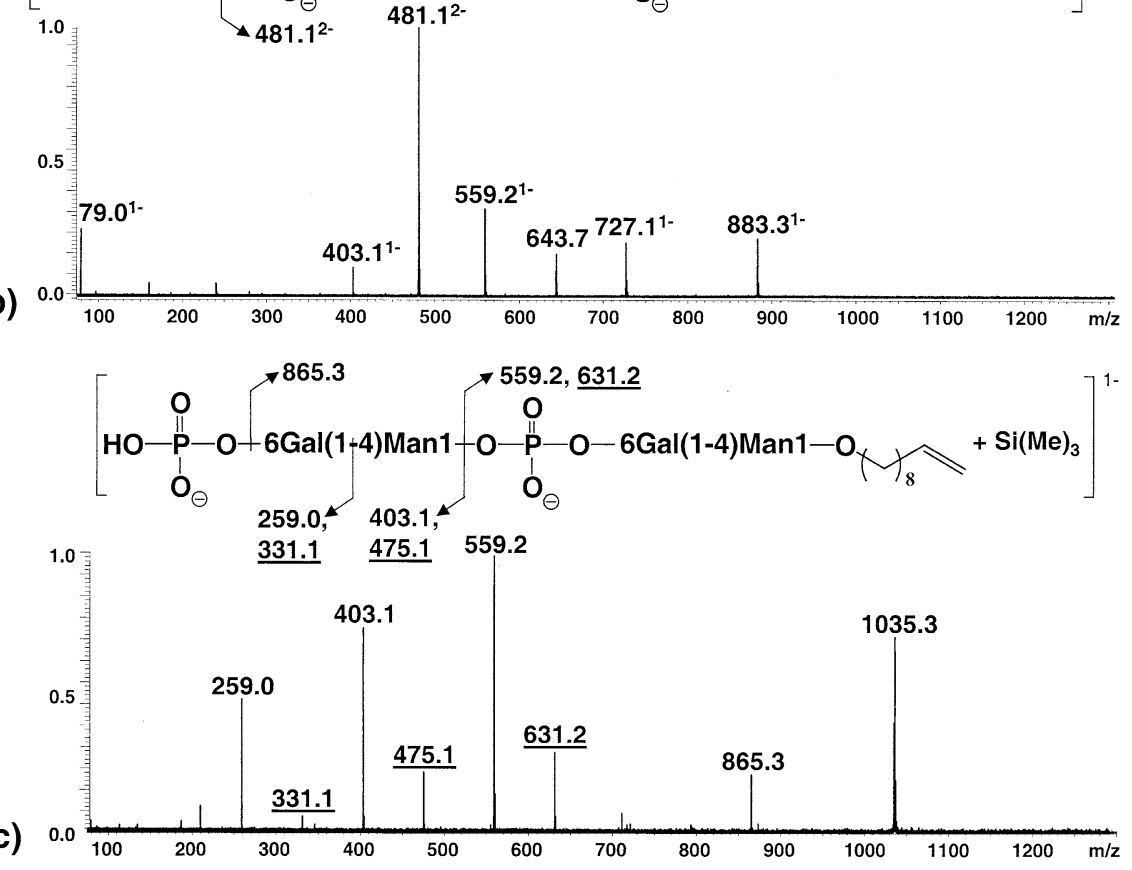

(d)

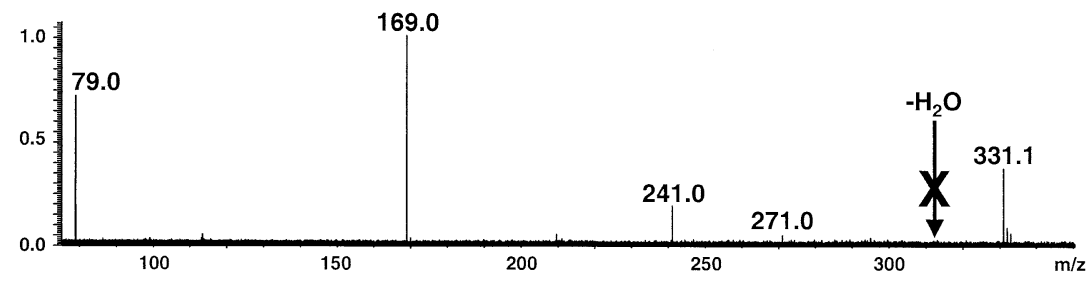

(e)
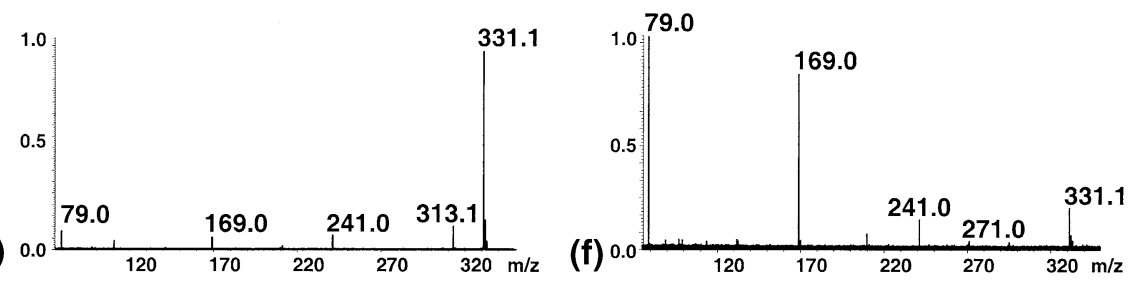

Figure 6. (a) $\mathrm{MS}^{1}$ of the lipophosphoglycan analog, generating an ion at $\mathrm{m} / \mathrm{z}$ 643.7. (b) Product ion spectrum of the doubly charged lipophosphoglycan analog $\left(\mathrm{MS}^{2} 643.7 \rightarrow\right)$, bond cleavages are noted on the inset. (c) Following CID of $\mathrm{m} / \mathrm{z} 643.7, \mathrm{~m} / \mathrm{z} 481.1$ was isolated and reacted with TMSCl yielding a singly charged species at $\mathrm{m} / \mathrm{z}$ 1035.3. Subjecting this ion to collisionally activated conditions (MS ${ }^{3}$ $643.7 \rightarrow 481.1+\mathrm{TMSCl} \rightarrow 1035.3 \rightarrow$ ) yielded several product ions resulting from glycosidic cleavages. The ions containing TMS are underlined in the figure. (d) Isolation and further reaction of $\mathrm{m} / \mathrm{z} 259.0$ with TMSCl, yielded an ion at $\mathrm{m} / \mathrm{z} 331.1$, which corresponds to [Gal6P/TMSCl- $\mathrm{HCl}{ }^{-}$. Subjecting $\mathrm{m} / \mathrm{z}$ 331.1 to collisionally activated conditions yielded the spectrum shown in the (d). Comparison of the product ions in (d) to those in (e) (Gal1P) and (f) (Gal6P) (and Table 1), illustrates that the phosphate was 6-linked to the galactose moiety. 
monosaccharide identification was determined through analysis of diagnostic product ions generated from tandem mass spectrometric analysis. In this work, the methodology was extended to larger oligomers with both internal and terminal phosphates through the use of the ion/molecule reagent TMSCl.

The hexose phosphates were initially investigated to ascertain the diagnostic ions generated for the monomeric species. Upon reaction of the HexP with TMSCl a single reaction product was observed at $\mathrm{m} / \mathrm{z}$ 331.1, corresponding to $[\mathrm{HexP} / \mathrm{TMSCl}-\mathrm{HCl}-\mathrm{H}]^{-}$. Upon subjecting this ion to CID, product ions were observed that allowed assignment of the phosphate linkage position. Furthermore the assignment of the stereochemistry of the hydroxyl group adjacent to the phosphate moiety was possible in the 1-linked case. In addition, phosphate loss was minimized compared to the underivatized case.

Once the diagnostic ions were determined for the HexP's, the methodology was applied to Lac1P. The sample was analyzed by first reacting the phosphate with TMSCl to form the $\mathrm{HCl}$ elimination product. The sample was then subjected to CID, which yielded an ion at $\mathrm{m} / \mathrm{z} 331.1$, corresponding to a derivatized monosaccharide species (as was formed with the HexP's above). Subjecting $\mathrm{m} / \mathrm{z} 331.1$ to collisionally activated conditions and comparison to Glc1P and Glc6P standards yielded product ions that agreed with the Glc1P isomer. This example shows that phosphate position as well as monosaccharide stereochemical information can be obtained from larger oligomers.

With the knowledge that the ion/molecule methodology works for oligomers with terminating phosphates, it was of interest to test larger oligomers with bridging phosphates. A sample exhibiting this characteristic is a lipophosphoglycan from the protozoan parasite Leishmania. To generate a terminating phosphate, the sample was subjected to collisionally activated conditions without TMS derivatization. Upon generation of a terminating phosphate, the sample was derivatized with TMS and again subjected to CID, generating the derivatized monomer species discussed above. Subjecting this ion to tandem mass spectrometric analysis and comparison to monosaccharide standards yielded phosphate linkage position and monosaccharide stereochemical information.

Thus, this methodology has been successfully applied to phosphorylated oligomers with both terminating and bridging phosphates. The general strategy for phosphate linkage position assignment is to generate a terminating phosphate through CID (in the case of bridging phosphates), react the terminal phosphate with TMSCl, and generate a derivatized HexP through collisional activation. Upon comparison of CID of derivatized monosaccharide standards with that generated through successive CID analysis of the larger oligomer, phosphate linkage position may be assigned.

\section{Acknowledgments}

JAL and MDL gratefully acknowledge NIH grant number GM47356 for funding. They thank Professor Michael A. J. Ferguson and Dr. Andrei Nikolaev of the University of Dundee (Scotland, UK) for generously providing the LPS analog analyzed in this study.

\section{References}

1. Leavell, M. D.; Kruppa, G. H.; Leary, J. A. Analysis of Phosphate Position in Hexose Monosaccharides Using Ion/ Molecule Reactions and SORI-CID on an FT-ICR Mass Spectrometer. Anal. Chem. 2002, 74, 2608-2611.

2. Leavell, M. D.; Kruppa, G. H.; Leary, J. A. Determination of Phosphate Position in Hexose Monosaccharides Using an FTICR Mass Spectrometer: Ion/Molecule Reactions, Labeling Studies, and Dissociation Mechanisms. Int. J. Mass Spectrom., 2003, 222, pp 135-153.

3. Voet, D.; Voet, J. G. Biochemistry. Wiley: New York, 1990, pp 425-443.

4. Marquardt, T.; Freeze, H. Congenital Disorders of Glycosylation: Glycosylation Defects in Man and Biological Models for Their Study. Biol. Chem. 2001, 382, 161-177.

5. Helenius, A.; Aebi, M. Intracellular Functions of N-Linked Glycans. Science 2001, 291, 2364-2369.

6. Swords, W. E.; Buscher, B. A.; Li, K. V. S.; Preston, A.; Nichols, W. A.; Weiser, J. N.; Gibson, B. W.; Apicella, M. A. NonTypeable Haemophilus influenzae Adhere to and Invade Human Bronchial Epithelial Cells via an Interaction of Lipooligosaccharide with the PAF Receptor. Mol. Microbiol. 2000, 37, 13-27.

7. White, K. A.; Lin, S. H.; Cotter, R. J.; Raetz, C. R. H. A Haemophilus influenzae Gene That Encodes a Membrane Bound 3-Deoxy-D-Manno-Octulosonic Acid (Kdo) KinasePossible Involvement of Kdo Phosphorylation in Bacterial Virulence. J. Biol. Chem. 1999, 274, 31391-31400.

8. Lee, N. G.; Sunshine, M. G.; Engstrom, J. J.; Gibson, B. W.; Apicella, M. A. Mutation of the Htrb Locus of Haemophilus influenzae Nontypable Strain 2019 is Associated with Modifications of Lipid A and Phosphorylation of the Lipo-Oligosaccharide. J. Biol. Chem. 1995, 270, 27151-27159.

9. Descoteaux, A.; Turco, S. J. Glycoconjugates in Leishmania infectivity. Bba-Mol. Basis Dis. 1999, 1455, 341-352.

10. Beverley, S. M.; Turco, S. J. Lipophosphoglycan (LPG) and the Identification of Virulence Genes in the Protozoan Parasite Leishmania. Trends Microbiol. 1998, 6, 35-40.

11. Ilg, T. Proteophosphoglycans of Leishmania. Parasitol. Today 2000, 16, 489-497.

12. Dass, C. Principles and Practice of Biological Mass Spectrometry. John Wiley: New York, 2001, pp 394-397.

13. McLachlin, D. T.; Chait, B. T. Analysis of Phosphorylated Proteins and Peptides by Mass Spectrometry. Curr. Opin. Chem. Biol. 2001, 5, 591-602.

14. Zinbo, M.; Sherman, W. R. Gas Chromatography and Mass Spectrometry of Trimethylsilyl Sugar Phosphates. J. Am. Chem. Soc. 1970, 92, 2105.

15. Harvey, D. J.; Horning, M. G. Characterization of Trimethylsilyl Derivatives of Sugar Phosphates and Related Compounds by Gas-Chromatography and Gas-Chromatography Mass-Spectrometry. J. Chromatogr. 1973, 76, 51-62.

16. Feurle, J.; Jomaa, H.; Wilhelm, M.; Gutsche, B.; Herderich, M. Analysis of Phosphorylated Carbohydrates by High-Performance Liquid Chromatography-Electrospray Ionization Tandem Mass Spectrometry Utilizing a $\beta$-Cyclodextrin Bonded Stationary Phase. J. Chromatogr. A 1998, 803, 111-119. 
17. Jensen, U. G.; Brandt, N. J.; Christensen, E.; Skovby, F.; Norgaard-Pedersen, B.; Simonsen, H. Neonatal Screening for Galactosemia by Quantitative Analysis of Hexose Monophosphates Using Tandem Mass Spectrometry: A Retrospective Study. Clin. Chem. 2001, 47, 1364-1372.

18. Green, M. K.; Lebrilla, C. B. Ion/Molecule Reactions as Probes of Gas-Phase Structures of Peptides and Proteins. Mass Spectrom. Rev. 1997, 16, 53-71.

19. Brodbelt, J. S. Analytical Applications of Ion/Molecule Reactions. Mass Spectrom. Rev. 1997, 16, 91-110.

20. Leeck, D. T.; Ranatunga, T. D.; Smith, R. L.; Partanen, T.; Vainiotalo, P.; Kenttamaa, H. I. Differentiation of Stereoisomeric Diols by Using Ch3ob + Och3 in a Small Fourier Transform Ion Cyclotron Resonance Mass Spectrometer. Int. J. Mass Spectrom. Ion Processes 1995, 141, 229-240.

21. Thoen, K. K.; Gao, L.; Ranatunga, T. D.; Vainiotalo, P.; Kenttamaa, H. I. Stereoselective Chemical Ionization Mass Spectrometry: Reactions of $\mathrm{CH} 3 \mathrm{OPOCH} 3+$ with Cyclic Vicinal Diols. J. Org. Chem. 1997, 62, 8702-8707.

22. Petucci, C.; Guler, L.; Kenttamaa, H. I. Differentiation of Stereoisomeric Steroids by Reactions with Phosphenium Ions. J. Am. Soc. Mass Spectrom. 2002, 13, 362-370.

23. Reid, G. E.; Tichy, S. E.; Perez, J.; O'Hair, R. A. J.; Simpson, R. J.; Kenttamaa, H. I. N-Terminal Derivatization and Fragmentation of Neutral Pepeides via Ion/Molecule Reactions with Acylium Ions: Toward Gas-Phase Edman Degradation? J. Am. Chem. Soc. 2001, 123, 1184-1192.

24. Grigorean, G.; Ramirez, J.; Ahn, S. H.; Lebrilla, C. B. A Mass Spectrometry Method for the Determination of Enantiomeric Excess in Mixtures of D,L-Amino Acids. Anal. Chem. 2000, 72, $4275-4281$.

25. Grigorean, G.; Lebrilla, C. B. Enantiomeric Analysis of Pharmaceutical Compounds by Ion/Molecule Reactions. Anal. Chem. 2001, 73, 1684-1691.

26. Grigorean, G.; Gronert, S.; Lebrilla, C. B. Enantioselective Gas-Phase Ion/Molecule Reactions in a Quadrupole Ion Trap. Int. J. Mass Spectrom. 2002, 219, 79-87.

27. Gronert, S.; O'Hair, R. A. J. Gas Phase Reactions of Trimethyl Borate with Phosphates and Their Non-Covalent Complexes. J. Am. Soc. Mass Spectrom. 2002, 13, 1088-1098.

28. Reid, G. E.; Shang, H.; Hogan, J. M.; Lee, G. U.; McLuckey, S. A. Gas-Phase Concentration, Purification, and Identification of Whole Proteins from Complex Mixtures. J. Am. Chem. Soc. 2002, 124, 7353-7362.
29. O'Hair, R. A. J.; McLuckey, S. A. Trimethylsilyl Derivatization of Nucleic Acid Anions in the Gas Phase. Int. J. Mass Spectrom. Ion Processes 1997, 162, 183-202.

30. Nikolaev, A. V.; Rutherford, T. J.; Ferguson, M. A. J.; Brimacombe, J. S. Parasite Glycoconjugates. 4. Chemical Synthesis of Disaccharide and Phosphorylated Oligosaccharide Fragments of Leishmania-Donovani Antigenic Lipophosphoglycan. J. Chem. Soc. Perkin Trans. 1995, 1, 1977-1987.

31. Senko, M. W.; Hendrickson, C. L.; Emmett, M. R.; Shi, S. D. H.; Marshall, A. G. External Accumulation of Ions for Enhanced Electrospray Ionization Fourier Transform Ion Cyclotron Resonance Mass Spectrometry. J. Am. Soc. Mass Spectrom. 1997, 8 , 970-976.

32. deKoning, L. J.; Nibbering, N. M. M.; vanOrden, S. L.; Laukien, F. H. Mass Selection of Ions in a Fourier Transform Ion Cyclotron Resonance Trap Using Correlated Harmonic Excitation Fields (CHEF). Int. J. Mass Spectrom. Ion Processes 1997, 165, 209-219.

33. Gauthier, J. W.; Trautman, T. R.; Jacobson, D. B. Sustained Off-Resonance Irradiation for Collision-Activated Dissociation Involving Fourier Transform Mass Spectrometry-CollisionActivated Dissociation Technique that Emulates Infrared Multiphoton Dissociation. Anal. Chim. Acta 1991, 246, 211-225.

34. Desaire, H.; Leary, J. A. Differentiation of Diastereomeric N-Acetylhexosamine Monosaccharides Using Ion Trap Tandem Mass Spectrometry. Anal. Chem. 1999, 71, 1997-2002.

35. Desaire, H.; Leary, J. A. Multicomponent Quantification of Diastereomeric Hexosamine Monosaccharides Using Ion Trap Tandem Mass Spectrometry. Anal. Chem. 1999, 71, 4142-4147.

36. Gaucher, S. P.; Leary, J. A. Stereochemical Differentiation of Mannose, Glucose, Galactose, and Talose Using Zinc(II) Diethylenetriamine and ESI-Ion Trap Mass Spectrometry. Anal. Chem. 1998, 70, 3009-3337.

37. Smith, G.; Leary, J. A. Mechanistic Studies of Diastereomeric Nickel(II) N-Glycoside Complexes Using Tandem Mass Spectrometry. J. Am. Chem. Soc. 1998, 120, 13046-13056.

38. Splitter, J. S.; Turecek, F. Applications of Mass Spectrometry to Organic Stereochemistry. VCH: New York, 1994.

39. Wilson, I. B. H.; O'Donnell, N.; Allen, S.; Mehlert, A.; Ferguson, M. A. J. Typing of Leishmania Lipophosphoglycans by Electrospray Mass Spectrometry. Mol. Biochem. Parasitol. 1999, 100, 207-215. 